\title{
A new pathway to curb inflammation
}

The cytokine interleukin-10 (IL-10), which is produced by various immune cells, has a crucial role in limiting inflammation. Recently, its production by distinct subsets of T cells, including $\mathrm{T}$ helper $1\left(\mathrm{~T}_{\mathrm{H}} 1\right)$ cells, has been described but the factors that induce its production by $\mathrm{T}$ cells are not fully understood. Another unresolved issue is the contradictory role of transforming growth factor- $\beta$ (TGF $\beta$ ) in the induction of both regulatory $\mathrm{T}$ cells and 'pro-inflammatory' $\mathrm{T}_{\mathrm{H}} 17$ cells. Now, four papers published in Nature Immunology address these issues, and identify a new pathway by which the immune system can restrain an inflammatory response.

Dendritic cells (DCs) can drive the differentiation of $\mathrm{T}$ cells, but they can also respond to factors produced by activated $\mathrm{T}$ cells and further regulate an ongoing immune response. Awasthi et al. investigated this process in an effort to understand the factors required for the induction of IL-10-producing T cells. They found that $\mathrm{FOXP}^{+}$(forkhead box P3) regulatory $\mathrm{T}$ cells, induced by TGF $\beta$, could modify DCs, which in turn could induce IL-10-producing T cells through the production of IL-27 and further amplify this response through the production of TGF $\beta$. These IL-10producing $\mathrm{T}$ cells also produced interferon- $\gamma$ (IFN $\gamma$ ) and expressed the transcription factor T-bet.

Stumhofer et al. also showed that IL-27 induced the production of IL- 10 by $\mathrm{CD}^{+}$and $\mathrm{CD}^{+} \mathrm{T}$ cells, and that

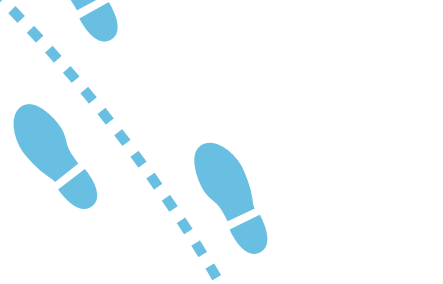

TGF $\beta$ enhanced this effect. IL-27 promoted the differentiation of T cells into IL-10-producing T cells under $\mathrm{T}_{\mathrm{H}} 1$ - and $\mathrm{T}_{\mathrm{H}} 2$ - but not $\mathrm{T}_{\mathrm{H}}$ 17-polarizing conditions, and the generation of these cells was dependent on the transcription factors STAT1 (signal transducer and activator of transcription 1) and STAT3. Interestingly, they found that, in the absence of IL-27, TGF $\beta$ plus IL-6 ( $\mathrm{T}_{\mathrm{H}}$ 17-polarizing conditions) induced a large population of $\mathrm{T}$ cells that produced IL-10 (with or without IL-17) in a STAT3-dependent manner, indicating that IL-6, as well as IL-27, can synergize with TGF $\beta$ to induce IL-10 production by T cells.

Under different experimental conditions, Fitzgerald et al. also identified a key role for IL-27 in the differentiation of $\mathrm{T}$ cells into IL- $10^{+}$IFN $\gamma^{+}$T-bet ${ }^{+} \mathrm{T}$ cells. Both the Stumhofer and Fitzgerald studies showed that IL-27 suppressed IL-17 production by $\mathrm{T}_{\mathrm{H}} 17$ cells, and this suppression was partially, but not completely, dependent on the induction of IL-10. In addition, Fitzgerald et al. showed that the exogenous administration of IL-27 reduced the severity of experimental autoimmune encephalomyelitis (EAE) induced by the adoptive transfer of $\mathrm{T}_{\mathrm{H}} 1$ cells in an IL-10dependent manner.

It is clear that TGF $\beta$ has an important role in the induction of $\mathrm{T}_{\mathrm{H}} 17$ cells in mice but there is still some confusion as to its role at later stages of the response - McGeachy et al. sought to clarify this issue. They showed that although TGF $\beta$ plus IL-6 induced continuous IL-17 production from myelin-reactive $\mathrm{T}$ cells, these cytokines induced $\mathrm{T}_{\mathrm{H}} 17$ cells that were non-pathogenic in an adoptive-transfer model of EAE. Only the transfer of $\mathrm{T}$ cells that had been stimulated in vitro with IL-23 induced disease. In addition, TGF $\beta$ plus IL- 6 but not IL-23 induced the production of IL-10 during the de novo generation of $\mathrm{T}_{\mathrm{H}} 17$ cells. This IL-10 was maintained by further stimulation with TGF $\beta$ plus IL-6 but was lost when the $T_{H} 17$ cells were restimulated with IL-23. This study suggests that TGF $\beta$ plus IL- 6 drive the differentiation of non-pathogenic $\mathrm{T}_{\mathrm{H}} 17$ cells that produce IL-10, which mediates a bystander regulatory response, thereby providing a means to regulate pathogenic $\mathrm{T}_{\mathrm{H}}$ 17-cell responses.

Together, these papers show a new mechanism by which the immune system can regulate an inflammatory immune response through the production of IL-27 - probably by DCs that have been modified by regulatory $\mathrm{T}$ cells - and the subsequent induction of IL-10-producing T cells. In addition, TGF $\beta$ can augment this response, and in the presence of IL-6 can directly promote the differentiation of non-pathogenic $T_{H} 17$ cells that produce IL-10.

Olive Leavy

ORIGINAL RESEARCH PAPERS Awasthi, A. et al. A dominant function for interleukin 27 in generating interleukin 10-producing antiinflammatory T cells. Nature Immunol.

11 November 2007 (doi:10.1038/ni1541) Stumhofer, J. S. et al. Interleukins 27 and 6 induce STAT3-mediated T cell production of interleukin 10. Nature Immunol. 11 November 2007 (doi:10.1038/ni1537) | Fitzgerald, D. C. et al. Suppression of autoimmune inflammation of the central nervous system by interleukin 10 secreted by interleukin 27-stimulated T cells. Nature Immunol. 11 November 2007 (doi:10.1038/ ni1540) | McGeachy, M. J. et al. TGF- $\beta$ and IL-6 drive the production of IL-17 and IL-10 by T cells and restrain $\mathrm{T}_{\mathrm{H}}-17$ cell-mediated pathology. Nature Immunol. 11 November 2007 (doi:10.1038/ni1539) 


\section{$\Rightarrow$ T-CELL ACTIVATION}

\section{A new pathway to curb}

The cytokine interleukin-10 (IL10 ), which is produced by various immune cells, has a crucial role in limiting inflammation. Recently, its production by distinct subsets of $\mathrm{T}$ cells, including $\mathrm{T}$ helper $1\left(\mathrm{~T}_{\mathrm{H}} 1\right)$ cells, has been described but the factors that induce its production by $\mathrm{T}$ cells are not fully understood. Another unresolved issue is the contradictory role of transforming growth factor- $\beta$ (TGF $\beta$ ) in the induction of both regulatory $\mathrm{T}$ cells and 'pro-inflammatory' $\mathrm{T}_{\mathrm{H}} 17$ cells. Now, four papers published in Nature Immunology address these issues, and identify a new pathway by which the immune system can restrain an inflammatory response.

Dendritic cells (DCs) can drive the differentiation of $\mathrm{T}$ cells, but they can also respond to factors produced by activated $\mathrm{T}$ cells and further regulate an on-going immune response. Awasthi et al. investigated this process in an effort to understand the factors required for the induction of IL-10-producing T cells. They found that $\mathrm{FOXP}^{+}$(forkhead box $\mathrm{P} 3)$ regulatory $\mathrm{T}$ cells, induced by TGF $\beta$, could modify DCs, which in turn could induce IL10 -producing $\mathrm{T}$ cells through the production of IL-27 and amplify this response through the production of TGF $\beta$. These induced $\mathrm{T}$ cells also produced interferon- $\gamma(\mathrm{IFN} \gamma)$ and expressed the transcription factor T-bet.

Stumhofer et al. also showed that IL-27 induced the production of IL- 10 by $\mathrm{CD}^{+}{ }^{+}$and $\mathrm{CD} 8^{+}$ $\mathrm{T}$ cells, and that TGF $\beta$ enhanced this effect. IL-27 promoted the differentiation of $\mathrm{T}$ cells into IL10-producing $\mathrm{T}$ cells in $\mathrm{T}_{\mathrm{H}} 1$ - and $\mathrm{T}_{\mathrm{H}} 2$ - but not $\mathrm{T}_{\mathrm{H}}$ 17-polarizing conditions, and the generation of these cells was dependent on the transcription factors STAT1 (signal transducer and activator of transcrip-

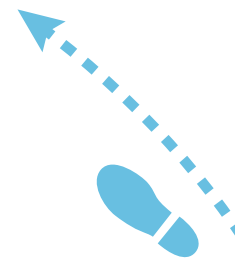

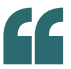

these papers show

a new mechanism

by which the

immune system

can regulate an

inflammatory

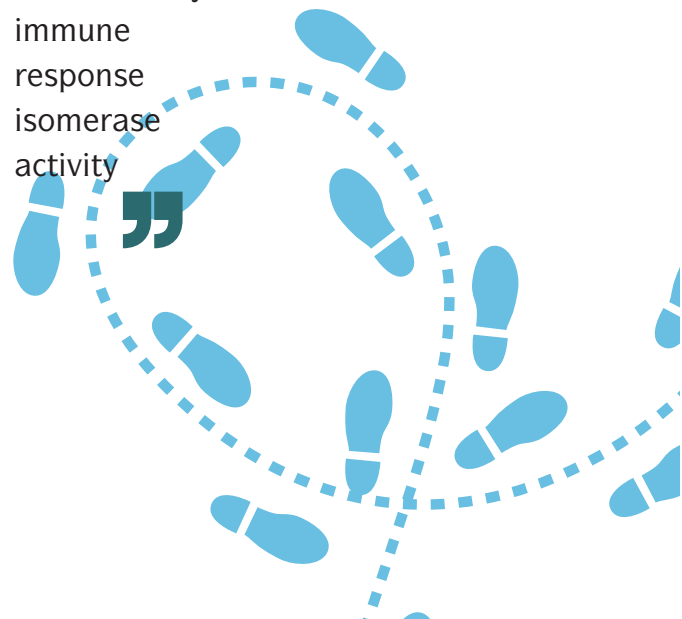

4 tion 1) and STAT3. Interestingly, they found that, in the absence of IL-27, TGF $\beta$ plus IL-6 ( $\mathrm{T}_{\mathrm{H}}$ 17-polarizing conditions) induced a large population of $\mathrm{T}$ cells that produced IL-10 (with or without IL-17) in a

4TAT3-dependent manner, indicat-

ing that IL-6, as well as IL-27, can

synergize with TGF $\beta$ to induce IL-10 production by $\mathrm{T}$ cells.

Under different experimental conditions, Fitzgerald et al. also identified a key role for IL-27 in the differentiation of $\mathrm{T}$ cells into IL- $10^{+}$IFN $\gamma^{+}$T-bet ${ }^{+} \mathrm{T}$ cells. Both the Stumhofer and Fitzgerald studies showed that IL-27 suppressed IL-17 production by $\mathrm{T}_{\mathrm{H}} 17$ cells, and this suppression was partially, but not completely, dependent on the induction of IL-10. In addition, Fitzgerald et al. showed that the exogenous administration of IL-27 reduced the severity of experimental autoimmune encephalomyelitis (EAE) induced by the adoptive transfer of $\mathrm{T}_{\mathrm{H}} 17$ cells (that had been generated in the presence of IL-23), in an IL- 10-dependent manner.

It is clear that TGF $\beta$ has an important role in the induction of $\mathrm{T}_{\mathrm{H}} 17$ cells in mice but there is still some confusion as to its role at later stages of the response - McGeachy et al. sought to clarify this issue. They showed that although TGF $\beta$ plus IL-6 induced continuous IL-17 production from myelin-reactive $\mathrm{T}$ cells, these cytokines induced $\mathrm{T}_{\mathrm{H}} 17$ cells that were non-pathogenic in an adoptive-transfer model of EAE. Only the transfer of T cells that had been stimulated in vitro with IL-23 induced disease. In addition, TGF $\beta$ plus IL- 6 but not IL-23 induced the production of IL-10 during the de novo generation of $\mathrm{T}_{\mathrm{H}} 17$ cells. This IL-10 was maintained by further stimulation with TGF $\beta$ plus IL- 6 but was lost when the $T_{H} 17$ cells were restimulated with IL-23. This study suggests that TGF $\beta$ plus IL- 6 drive the differentiation of non-pathogenic $\mathrm{T}_{\mathrm{H}} 17$ cells that produce IL-10, which mediates a bystander regulatory response, thereby providing a means to regulate pathogenic $\mathrm{T}_{\mathrm{H}} 17$-cell responses.

Together, these papers show a new mechanism by which the immune system can regulate an inflammatory immune response through the production of IL-27 - probably by DCs that have been modified by regulatory $T$ cells - and the subsequent induction of IL-10producing $\mathrm{T}$ cells. In addition, TGF $\beta$ can augment this response, and in the presence of IL- 6 can directly promote the differentiation of nonpathogenic $\mathrm{T}_{\mathrm{H}} 17$ cells that produce IL-10.

Olive Leavy

ORIGINAL RESEARCH PAPERS Awasthi, A. et al. A dominant function for interleukin 27 in generating interleukin 10-producing antiinflammatory T cells. Nature Immunol. 11 November 2007 (doi:10.1038/ni1541)| Stumhofer, J. S. et al. Interleukins 27 and 6 induce STAT3-mediated T cell production of interleukin 10. Nature Immunol. 11 November 2007 (doi:10.1038/ni1537)|Fitzgerald, D. C. et al. Suppression of autoimmune inflammation of the central nervous system by interleukin 10 secreted by interleukin 27-stimulated T cells. Nature Immunol. 11 November 2007 (doi:10.1038/ ni1540) | McGeachy, M. J. et al. TGF- $\beta$ and IL-6 drive the production of IL-17 and IL-10 by T cells and restrain $\mathrm{T}_{H}-17$ cell-mediated pathology. Nature Immunol. 11 November 2007 (doi:10.1038/ni1539) 


\section{A new pathway to to curb inflammation}

The cytokine interleukin-10 (IL-10), which is produced by various immune cells, has a crucial role in limiting inflammation. Recently, its production by distinct subsets of $\mathrm{T}$ cells, including $\mathrm{T}$ helper $1\left(\mathrm{~T}_{\mathrm{H}} 1\right)$ cells, has been described but the factors that induce its production by $\mathrm{T}$ cells are not fully understood. Another unresolved issue is the contradictory role of transforming growth factor- $\beta$ (TGF $\beta$ ) in the induction of both regulatory $\mathrm{T}$ cells and 'proinflammatory' $\mathrm{T}_{\mathrm{H}} 17$ cells. Now, four papers published in Nature Immunology address these issues, and identify a new pathway by which the immune system can restrain an inflammatory response.

Dendritic cells (DCs) can drive the differentiation of $\mathrm{T}$ cells, but they can also respond to factors produced by activated $\mathrm{T}$ cells and further regulate an on-going immune response. Awasthi et al. investigated this process in an effort to understand the factors required for the induction of IL-10-producing T cells. They found that $\mathrm{FOXP}^{+}$(forkhead box $\mathrm{P} 3)$ regulatory $\mathrm{T}$ cells, induced by TGF $\beta$, could modify DCs, which in turn could induce IL-10-producing $\mathrm{T}$ cells through the production of IL-27 and amplify this response through the production of TGF $\beta$. These induced T cells also produced interferon- $\gamma($ IFN $\gamma)$ and expressed the transcription factor T-bet.

Stumhofer et al. also showed that IL-27 induced the production of IL- 10 by $\mathrm{CD} 4^{+}$and $\mathrm{CD} 8^{+} \mathrm{T}$ cells, and that TGF $\beta$ enhanced this effect. IL-27 promoted the differentiation of T cells into IL-10-producing $\mathrm{T}$ cells in $\mathrm{T}_{\mathrm{H}} 1$ - and $\mathrm{T}_{\mathrm{H}} 2$ - but not $\mathrm{T}_{\mathrm{H}} 17$ polarizing conditions, and the generation of these cells was dependent on the transcription factors STAT1

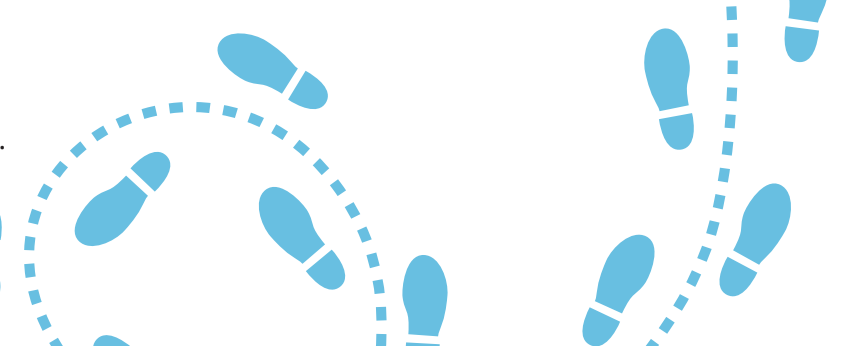

stimulation with TGF $\beta$ plus IL- 6 but was lost when the $\mathrm{T}_{\mathrm{H}} 17$ cells were restimulated with IL-23. This study suggests that TGF $\beta$ plus IL-6 drive the differentiation of nonpathogenic $\mathrm{T}_{\mathrm{H}} 17$ cells that produce IL-10, which mediates a bystander regulatory response, thereby providing a means to regulate pathogenic $\mathrm{T}_{\mathrm{H}} 17$-cell responses.

Together, these papers show a new mechanism by which the immune system can regulate an inflammatory immune response through the production of IL-27 - probably by DCs that have been modified by regulatory $\mathrm{T}$ cells - and the subsequent induction of IL-10-producing T cells. In addition, TGF $\beta$ can augment this response, and in the presence of IL-6 can directly promote the differentiation of non-pathogenic $\mathrm{T}_{\mathrm{H}} 17$ cells that produce IL-10.

Olive Leavy

ORIGINAL RESEARCH PAPERS Awasthi, A. et al. A dominant function for interleukin 27 in generating interleukin 10-producing antiinflammatory T cells. Nature Immunol. 11 November 2007 (doi:10.1038/ni1541)| Stumhofer, J. S. et al. Interleukins 27 and 6 induce STAT3-mediated T cell production of interleukin 10. Nature Immunol. 11 November 2007 (doi:10.1038/ni1537) | Fitzgerald, D. C.et al. Suppression of autoimmune inflammation of the central nervous system by interleukin 10 secreted by interleukin 27-stimulated T cells. Nature Immunol. 11 November 2007 (doi:10.1038/ ni1540) | McGeachy, M. J. et al. TGF- $\beta$ and IL-6 drive the production of IL-17 and IL-10 by T cells and restrain $\mathrm{T}_{\mathrm{H}}-17$ cell-mediated pathology. Nature Immunol. 11 November 2007 (doi:10.1038/ni1539) 